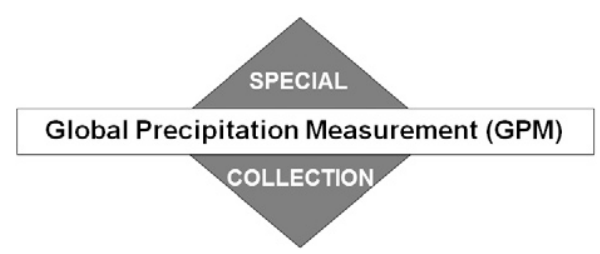

\title{
GPM Satellite Radar Observations of Precipitation Mechanisms in Atmospheric Rivers
}

\author{
FOREST CANNON \\ Center for Western Weather and Water Extremes, Scripps Institution of Oceanography, \\ University of California, San Diego, La Jolla, California \\ JASON M. CORDEIRA \\ Meteorology Program, Plymouth State University, Plymouth, New Hampshire
Chad W. Hecht, Joel R. Norris, Allison Michaelis, Reuben Demirdjian, AND F. MARTIN RALPH \\ Center for Western Weather and Water Extremes, Scripps Institution of Oceanography, \\ University of California, San Diego, La Jolla, California
}

(Manuscript received 23 August 2019, in final form 10 January 2020)

\begin{abstract}
Despite numerous studies documenting the importance of atmospheric rivers (AR) to the global water cycle and regional precipitation, the evolution of their water vapor fluxes has been difficult to investigate given the challenges of observing and modeling precipitation processes within ARs over the ocean. This study uses satellite-based radar reflectivity profiles from the Global Precipitation Measurement Dual-Frequency Precipitation Radar (GPM-DPR), combined with kinematic and thermodynamic conditions in the vicinity of the precipitation diagnosed from the Climate Forecast System Reanalysis, to evaluate the characteristics and dynamical origins of precipitation in ARs over the northeast Pacific Ocean. Transects of 192 ARs between 2014 and 2018 are examined. Both stratiform and convective precipitation were abundant in these GPM transects and the precipitation was most often generated by forced ascent in the vicinity of a cold front in frontogenetic environments. Conditioning composite vertical profiles of reflectivity and latent heating from GPM-DPR on frontogenesis near the moist-neutral low-level jet demonstrated the importance of frontally forced precipitation on atmospheric heating tendencies. A case study of a high-impact landfalling AR is analyzed using the Weather Research and Forecasting Model, which showed how the precipitation processes and subsequent latent heat release offshore strongly influenced AR evolution. Although these precipitation mechanisms are present in global-scale models, the difficulty that coarse-resolution models have in accurately representing resultant precipitation likely translates to uncertainty in forecasting heating tendencies, their feedbacks on AR evolution, and ultimately the impacts of ARs upon landfall in the western United States.
\end{abstract}

\section{Introduction}

Atmospheric rivers (AR) are a key component of the global water budget that account for a major fraction of precipitation in the western portions of midlatitude continents, including the west coast of North America (e.g., Zhu and Newell 1998; Ralph et al. 2004, 2017a; Dettinger 2013; Lavers et al. 2016). Despite the importance of ARs to global moisture fluxes and regional

Corresponding author: Forest Cannon, fcannon@ucsd.edu water resources, observing, understanding and predicting their evolution is complicated by the challenges of observing and modeling the frequency, location and intensity of precipitation mechanisms over the ocean (Neiman et al. 2016). There are several previous studies examining precipitation in oceanic ARs based on large observational datasets (e.g., Ralph et al. 2004); however, these studies collectively demonstrate a need for additional analyses of the dynamical processes that produce observed precipitation and that illustrate how concomitant latent heating may drive subsequent changes in the 
thermodynamic structure of ARs. Thus, the objectives of this paper are to define how and where precipitation is typically generated in ARs and whether it influences an event's continued evolution. This investigation is motivated by a need to identify potential sources of global forecast model simulation error that limit the predictability of North Pacific ARs prior to landfall along the west coast of North America.

In a study by Ralph et al. (2004), satellite-derived observations of cloud liquid water and rain rate by the Special Sensor Microwave Imager (SSM/I) over the Pacific Ocean identified large values of both quantities on the northern (poleward) side of ARs that likely demonstrate the presence of slantwise baroclinic ascent on the cold sector side of the integrated water vapor plumes, as shown via numerical model data in Cordeira et al. (2013). The SSM/I-based study did not investigate the mechanisms responsible for producing precipitation or the potential impact of these mechanisms on the evolution of the attendant cyclone, the cold front, or water vapor transport (e.g., Lackmann 2002; Cordeira et al. 2013; Booth et al. 2018) as the observations available at that time were not well suited to the problem nor considered alongside suitable numerical data. However, AR precipitation mechanisms may now be investigated using measurements of precipitation reflectivity from the Dual-Frequency Precipitation Radar (DPR) on board the recently launched Global Precipitation Measurement Mission (GPM) satellite (Hou et al. 2014; SkofronickJackson et al. 2017, 2018). The observational dataset, combined with a high-resolution numerical dataset, provides the necessary data to expand upon the work of Ralph et al. (2004) to evaluate precipitation processes and the evolution of water vapor transport in oceanic ARs.

The motivation to evaluate precipitation processes in oceanic ARs using GPM-DPR is driven by the hypothesis that latent heat release associated with precipitation modifies the thermodynamic and kinematic processes of the mesoscale and synoptic-scale circulations of the AR (Kuo et al. 1991; Davis and Emanuel 1991; Lackmann 2002; Cordeira et al. 2013), and that global-scale model simulation of these processes is inadequate (Schäfler et al. 2018). Previous studies have shown that extratropical cyclone intensity (e.g., minimum sea level pressure or eddy kinetic energy) and precipitation can reinforce each other, with cyclone intensification leading to enhanced vertical motion, latent heat release and precipitation, and consequently, further intensification (Kuo et al. 1991; Davis and Emanuel 1991). Latent heat release associated with precipitation may also modify the frontal circulations of extratropical cyclones via enhanced frontogenesis (Baldwin et al.
1984; Hsie et al. 1984; Thorpe and Emanuel 1985; Chan and Cho 1991; Montgomery and Farrell 1991; Posselt and Martin 2004), increased frontal speed (e.g., Reeves and Lackmann 2004), or affect changes to the intensity of vertical velocity and rainbands (Martin and Otkin 2004) and water vapor transport magnitude in vicinity of the front (Lackmann 2002). For example, the generation of lower-tropospheric potential vorticity (PV) associated with midtropospheric latent heat release and frontal precipitation was found to contribute $15 \%-40 \%$ of the magnitude of the low-level jet (LLJ) in the warm sector of a cyclone, and exhibited a complex interdependence with warm sector moisture transport (Lackmann 2002). GPM-DPR is the first instrument capable of providing the vertically resolved reflectivity measurements that are necessary to evaluate these precipitation mechanisms over the midlatitude oceans, which further enables this study to investigate their impact on AR evolution.

The predictability of AR landfall and associated precipitation along the U.S. West Coast may also be tied to the skill of global forecast models in representing latent heating processes (Lavers et al. 2018) and their subsequent impacts on circulation (Lackmann and Gyakum 1999; Doyle et al. 2014). Thus, GPM-DPR-derived precipitation reflectivity profiles of ARs over the ocean may additionally be used to identify errors in global model simulation of precipitation mechanisms. As the amount and quality of assimilated observations in global forecast models is limited within the study region, understanding the primary precipitation mechanisms in ARs, challenges in simulating these mechanisms, and their impact on AR evolution are all important steps in identifying sources of AR landfall forecast errors (e.g., Ralph et al. 2010; Wick et al. 2013). The influence of the representation of latent heating in global forecasting models is an open and important direction of research that GPM-DPR-based evaluations of precipitation mechanisms are well suited to support.

The remainder of this paper is organized as follows: section 2 describes the observational and model datasets that were used in this study, as well as the steps taken to process and analyze them. Section 3 investigates the generation of precipitation and latent heating in an AR case study and section 4 evaluates these processes across a large number of AR cases. Section 5 concludes the manuscript with a brief summary and ideas for future work.

\section{Data and methods}

This study considers precipitation processes in ARs over the northeast Pacific $\left(20^{\circ}-50^{\circ} \mathrm{N}, 160^{\circ}-110^{\circ} \mathrm{W}\right)$ during 
four winter seasons (October through April) since the launch of the GPM satellite in 2014 through 2018 (i.e., October 2014 through April 2018). ARs are defined based on criteria established by Rutz et al. (2014) as long $(>2000 \mathrm{~km})$, narrow corridors of integrated water vapor transport (IVT) magnitude $>250 \mathrm{~kg} \mathrm{~m}^{-1} \mathrm{~s}^{-1}$ calculated from the National Centers for Environmental Prediction (NCEP) Climate Forecast System Reanalysis and operational analysis (CFSR) datasets (Saha et al. 2010, 2014). The NCEP-CFSR data are available on a $0.5^{\circ}$ latitude $\times$ $0.5^{\circ}$ longitude horizontal grid every $6 \mathrm{~h}$ at 0000,0600 , 1200 , and 1800 UTC for the reanalysis period (19792011) and for the operational period (2011 to present). The NCEP-CFSR data are also used to calculate and derive meteorological parameters commonly invoked in mesoscale and synoptic-analyses of fronts including geopotential height, water vapor mixing ratio, wind, equivalent potential temperature $\left(\theta_{e}\right)$, convectively available potential energy (CAPE), integrated water vapor (IWV), and IVT. The latter is calculated for the column extending from the surface to $200 \mathrm{hPa}$.

Precipitation processes in ARs are evaluated using version 5 of the GPM-DPR-derived standard level 2 (L2) radar reflectivity (in three dimensions), and precipitation rate (e.g., Iguchi et al. 2010) for swaths over the same aforementioned northeast Pacific domain. The GPM-DPR utilizes differential attenuation between $\mathrm{Ku}$-band $(13.6 \mathrm{GHz})$ and $\mathrm{Ka}$-band $(35.5 \mathrm{GHz})$ radars within the matched beam swath to provide information on drop size distributions and precipitation intensity that improve precipitation rate estimation relative to other satellite sensors (Skofronic-Jackson et al. 2017). The reflectivity data have a vertical bin sampling of $125 \mathrm{~m}$ (176 vertical bins) and a horizontal resolution of $\sim 5.2 \mathrm{~km}$ for a swath width of $\sim 125 \mathrm{~km}$ ( 25 horizontal bins in the across-swath direction). Analyses here consider only data from the clutter-free bins, which are generally found above $0.5 \mathrm{~km}$ at nadir and between 1 and $1.5 \mathrm{~km}$ at the edge of the swath. Although the GPM-DPR infrequently samples precipitation processes along a narrow pseudopolar orbiting swath, individual reflectivity profiles of the precipitation features it samples across the western United States compare favorably with ground measurements (Cannon et al. 2017). A suite of algorithms is also able to derive information about the characteristics of observed precipitation, including snow versus rain discrimination, freezing level height estimation, and discernment of convective and stratiform precipitation types (Iguchi et al. 2010; Awaka et al. 2016). Additionally, we evaluate spectral latent heating (SLH) estimates from the GPMSLH V6 product suite (Iguchi et al. 2018). The SLH product is derived by combining the GPM Ku-band

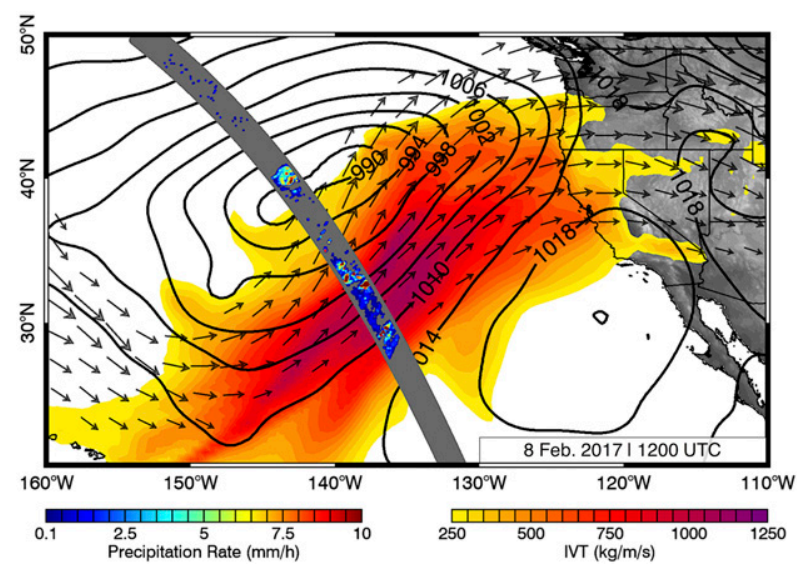

FIG. 1. IVT magnitude ( $\mathrm{kg} \mathrm{m}^{-1} \mathrm{~s}^{-1}$; shaded according to scale), mean sea level pressure (hPa; contours every $4 \mathrm{hPa}$ ), and 250-hPa winds (vectors; minimum of $40 \mathrm{~m} \mathrm{~s}^{-1}$ and maximum of $100 \mathrm{~m} \mathrm{~s}^{-1}$ ) at 1200 UTC 8 Feb 2017. The black swath indicates the GPM-DPR transect at $\sim 1040$ UTC on the same date, with precipitation estimates at each bin $\left(\mathrm{mm} \mathrm{h}^{-1}\right.$; shaded according to scale).

observed reflectivity profiles with lookup table information generated from cloud-resolving model simulations of extratropical cyclones to return pseudo-observed vertical heating profiles that correspond well to independent high-resolution simulation (Takayabu et al. 2017; Iguchi et al. 2018).

An example of the GPM-DPR spatial coverage for a precipitating swath intersecting an AR over the northeast Pacific is shown for 8 February 2017 during the landfall of a high-impact AR in California (Fig. 1) that produced notable damages and insured losses (Vano et al. 2019). The figure demonstrates the minimal spatial coverage of the instrument within a single CFSR time step; however, the orientation of the swath relative to the elongated nature of southwest-northeast-oriented ARs is well suited to collect a large number of samples over the course of multiple winter seasons. For example, the percentage of GPM overpasses with precipitation retrievals is largest $(15 \%-20 \%)$ within and north of the region of enhanced AR activity (i.e., regions with $50 \%$ likelihood of an "AR day") in the northwest portion of the study domain (Fig. 2).

Our study considers only those ARs derived from the NCEP-CFSR datasets over the northeast Pacific that contained GPM-DPR-derived precipitation as illustrated in Fig. 1, and includes 192 independent GPM overpasses of ARs over the northeast Pacific during the four cool-season study period. This number of overpasses is sensitive to several qualitative decisions that were made in developing the methodology, which were executed to limit analyses to unambiguous AR cases with ideal overpass geometry and timing. Notably, event 


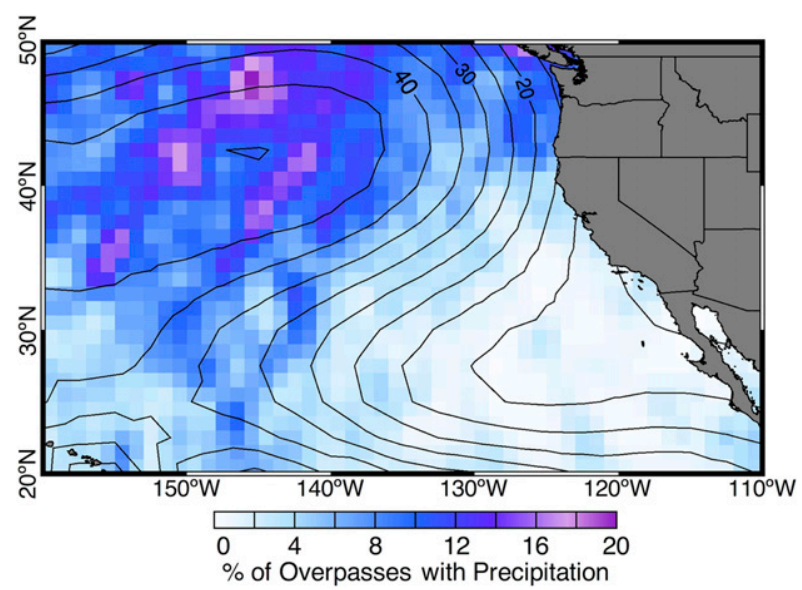

FIG. 2. Seasonal (October-April) average percentage of days with an AR (\%; contours) based on the methodology of Rutz et al. (2014) and the percentage of GPM-DPR overpasses that retrieved precipitation ( $\%$; shaded according to scale and rebinned to $1^{\circ} \times$ $1^{\circ}$ grid spacing for generalization).

selection was restricted to clearly defined ARs that met the Rutz et al. (2014) criterion, that were fully transected by a GPM overpass at an angle between $90^{\circ}$ and $45^{\circ}$, and that contained precipitation within the region of $\mathrm{AR}$ conditions (i.e., IVT $>250 \mathrm{~kg} \mathrm{~m}^{-1} \mathrm{~s}^{-1}$ ). This geometry restriction enabled a systematic evaluation of GPM observations across AR transects in which all data could be centered and distance-normalized relative to the time and location of the maximum IVT magnitude following the methodology of Ralph et al. (2017b; see next paragraph). To obtain a sufficiently large sample, a 1.5-h time difference between the 6-h reanalysis time step and the satellite overpass time was allowed. While Cannon et al. (2017) demonstrated some negative impacts associated with point-based freezing level comparisons between GPM-DPR observations and in situ observations at differing times, the transect analyses presented here are less sensitive to small time differences given the much larger spatial scale considered. The 192 transects evaluated in the present study sampled ARs with a range in magnitude from weak (IVT $=250 \mathrm{~kg} \mathrm{~m}^{-1} \mathrm{~s}^{-1}$ ) to extreme (IVT $>1250 \mathrm{~kg} \mathrm{~m}^{-1} \mathrm{~s}^{-1}$; Fig. 3).

In the present study, GPM transects of ARs were created following the methodology of Ralph et al. (2017b) who summarized the general synoptic conditions of ARs using 21 transects derived from dropsonde measurements of ARs sampled during the CalWater field campaigns (see their Fig. 16b). Individual GPM transects of ARs and their corresponding CFSR data are centered on the location of the maximum IVT magnitude and normalized by the average width of the region where IVT exceeded $250 \mathrm{~kg} \mathrm{~m}^{-1} \mathrm{~s}^{-1}$ in each of the transects. Similarities between a composite of these

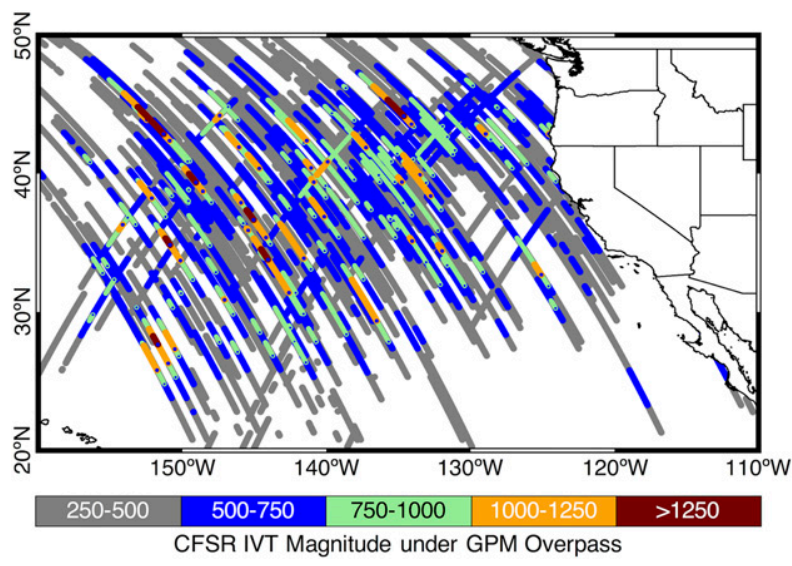

FIG. 3. GPM-DPR swath locations across AR features within the study domain for the period October-April 2014-18. Each of 192 transects is color-coded according to the magnitude of IVT $\left(\mathrm{kg} \mathrm{m}^{-1} \mathrm{~s}^{-1}\right)$.

transects (Fig. 4) and the dropsonde transects derived by Ralph et al. (2017b) include a maximum in averaged water vapor mixing ratio that occurs near the maximum in IVT magnitude, which is collocated with the maximum winds in the LLJ near the center of the AR. The LLJ transports moisture parallel to and ahead (south) of a cold front that extends from the surface on the coldsector side of the IVT maximum toward the upper-level jet at $250 \mathrm{hPa}$ positioned several hundred $\mathrm{km}$ to the north. Precipitation in both CFSR and GPM observations peaks on the cold-sector side of the IVT maximum, ahead of the cold front, though CFSR estimates are roughly $80 \%$ smaller than GPM observations (Fig. 4).

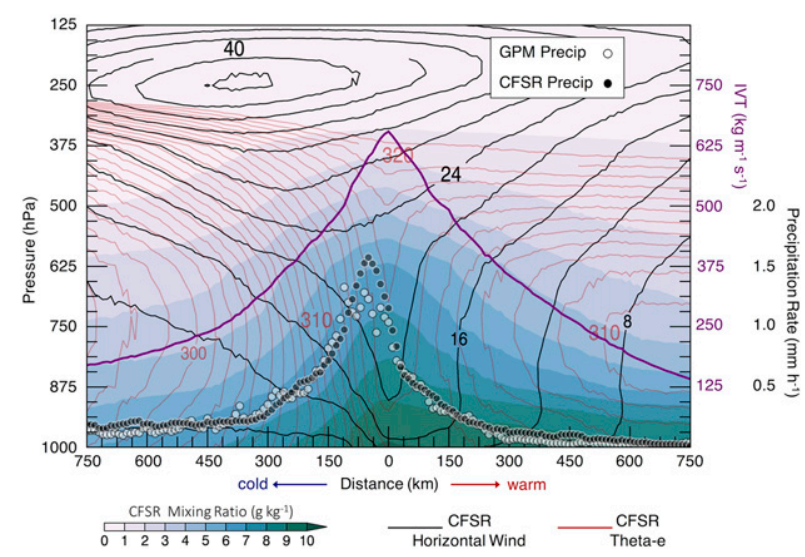

FIG. 4. Composite cross section of 192 AR transects centered and distance-normalized upon their IVT maxima. CFSR wind magnitude (black contours every $4 \mathrm{~m} \mathrm{~s}^{-1}$ ), $\theta_{e}$ (red contours every $2 \mathrm{~K}$ ), and water vapor mixing ratio $\left(\mathrm{g} \mathrm{kg}^{-1}\right.$; colorfill) are shown in two dimensions. CFSR IVT $\left(\mathrm{kg} \mathrm{m}^{-1} \mathrm{~s}^{-1}\right.$; purple line $)$, and precipitation from GPM-DPR $\left[\mathrm{mm} \mathrm{h}^{-1}\right.$ (divided by 5); white dots] and CFSR $\left(\mathrm{mm} \mathrm{h}^{-1}\right.$; black dots) are overplotted. 

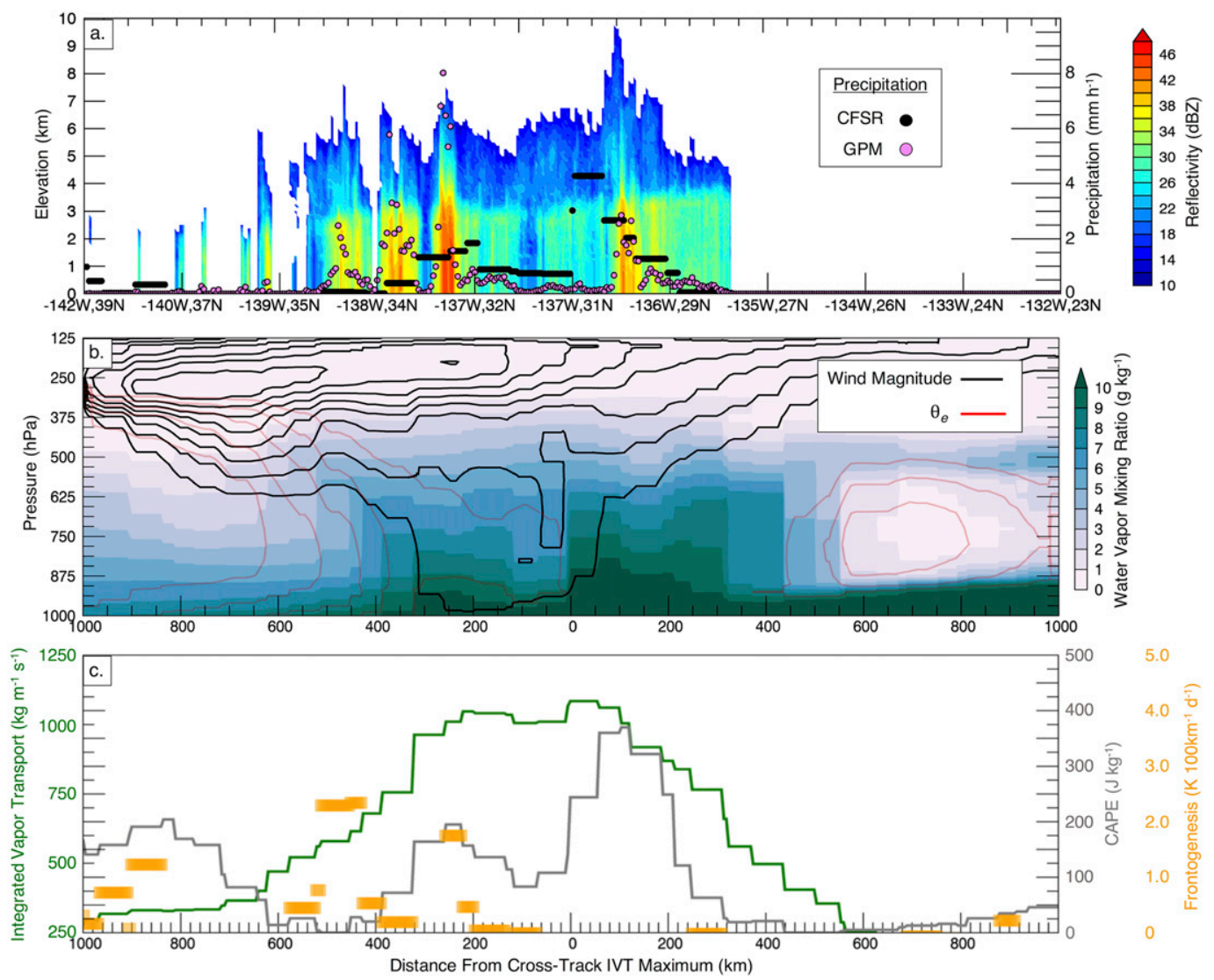

FIG. 5. (a) GPM-DPR maximum cross-track reflectivity transect (dBZ; colorfill) across the AR shown in Fig. 1, with mean cross-track precipitation from GPM $\left(\mathrm{mm} \mathrm{h}^{-1}\right.$; purple) and CFSR $\left(\mathrm{mm} \mathrm{h}^{-1}\right.$; black) overplotted in one dimension. (b) The corresponding CFSR wind magnitude ( $\mathrm{m} \mathrm{s}^{-1}$; black contour), $\theta_{e}$ (K; red contour), and water vapor mixing ratio (colorfill), and (c) the CFSR CAPE, IVT magnitude, and 850-hPa frontogenesis (K $100 \mathrm{~km}^{-1} \mathrm{~d}^{-1}$ ) along the AR transect.

Note that although the improved representation of the hydrologic cycle by CFSR relies on assimilating precipitation estimates, including those from the GPM microwave imager, the GPM-DPR measurements evaluated here are not assimilated and, therefore, are independent.

The observed and modeled precipitation amount disparity is partially related to the coarse gridscale resolution of CFSR, which averages out intense precipitation, though reconciling these amounts by statistical upscaling alone would not overcome fundamental limitations in the model's ability to simulate precipitation amounts that are related to parameterization and gridscale resolution (Saha et al. 2010, 2014). Thus, we proceed using GPM-DPR retrievals as our "ground truth" in this framework. Regardless, the ability of the CFSR profiles along GPM transects to represent the primary circulation features found in observation-based studies lends confidence to our evaluation of precipitation mechanisms within this framework.
Finally, the open-source Advanced Research version of the Weather Research and Forecasting (WRF) Model (Skamarock et al. 2008) is used here to simulate the role of latent heating from precipitation in an AR for a single impactful event on 8 February 2017 (event shown in Fig. 1). These experiments consist of a control simulation and a modified simulation, with the latter simulation run without cumulus parameterization and no latent heating from the microphysics parameterization scheme (e.g., Reeves and Lackmann 2004). The WRF simulations were configured with two domains with horizontal grid spacing of 9 and $3 \mathrm{~km}$, respectively, and 60 vertical levels. The nested one-way interacting WRF domains were centered over the nexus of the AR and GPM transect at 1200 UTC 8 February and initialized $24 \mathrm{~h}$ prior with CFSR as initial and boundary conditions.

The parameterized physics options used in these simulations include the Rapid Radiative Transfer Model (RRTM; Mlawer et al. 1997)—which is used for both shortwave and longwave spectral bands, the revised MM5 


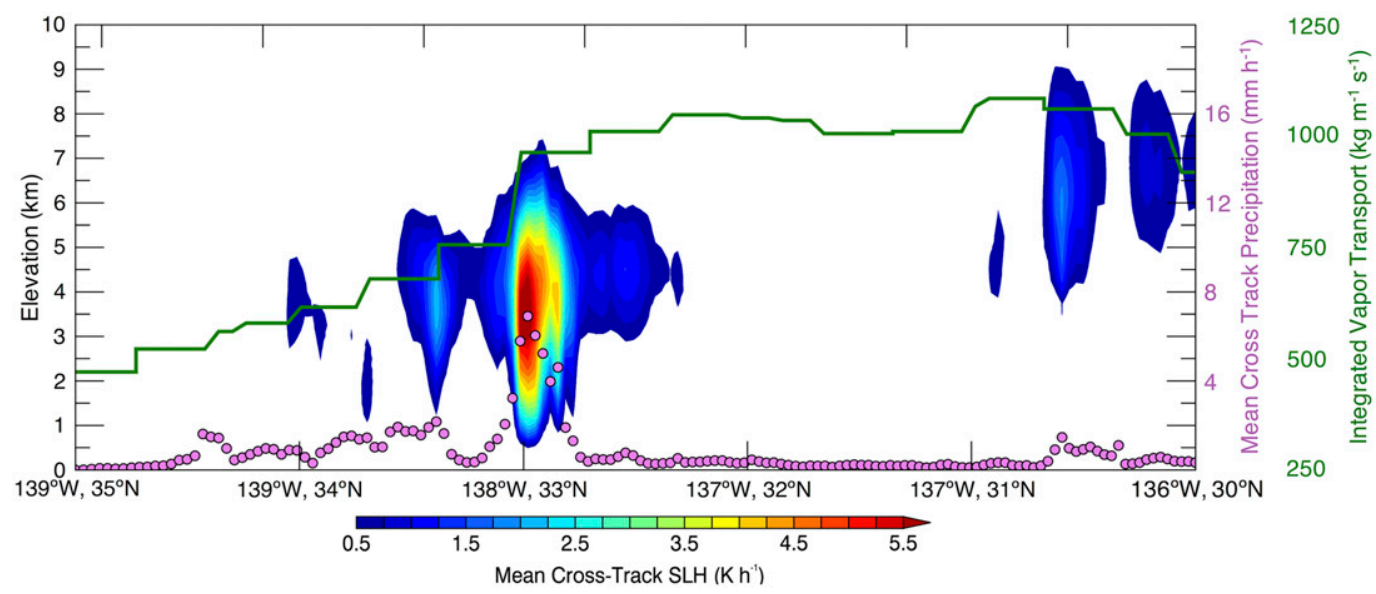

FIG. 6. Vertical profile of mean GPM spectral latent heating estimates ( $\mathrm{K} \mathrm{h}^{-1}$; colorfill) across the AR shown in Fig. 1, with mean precipitation from GPM $\left(\mathrm{mm} \mathrm{h}^{-1}\right.$; purple symbols) and CFSR IVT $\left(\mathrm{kg} \mathrm{m}^{-1} \mathrm{~s}^{-1}\right.$; green line) overplotted.

surface layer scheme (Jiménez, et al. 2012), the YSU PBL scheme (Hong et al. 2006), the new Thompson microphysics scheme (Thompson et al. 2008), and the scale-aware Grell-3D convective parameterization scheme (Grell and Devenyi 2002), which is only used in the control simulation's outer domain. This WRF physics configuration is based upon Martin et al. (2018), which provided the basis for the selected model configuration on account of its efficacy in simulating AR conditions observed by dropsondes during the Atmospheric River Reconnaissance and CalWater field campaigns over the northeast Pacific study region in 2015 and 2016 (Ralph et al. 2016). For brevity and because of the comparatively small spatial extent of the nested domain, only results from the outer $9 \mathrm{~km}$ domain are shown, though it is important to note that the concepts discussed in this manuscript regarding the interdependency of frontal precipitation and AR evolution are consistent between domains.

\section{Results: 8 February 2017 case study}

\section{a. GPM observations and CFSR reanalysis}

On 8 February 2017 a GPM overpass intersected an extreme AR (based on categories established by Ralph et al. 2017b) that extended from Hawaii to the U.S. West Coast (Fig. 1). Precipitation in the northern Sierra Nevada region driven by this AR was an important contributor to the Oroville spillway incident (White et al. 2019; Vano et al. 2019), which led to the evacuation of nearly 200000 people from Yuba County, California. The evolution of the synoptic-scale pattern prior to 8 February 2017 is illustrated by White et al. (2019) and was associated with the persistent landfall of multiple
ARs with IVT magnitudes $>1000 \mathrm{~kg} \mathrm{~m}^{-1} \mathrm{~s}^{-1}$ along the California coast during the several days leading up to 8 February 2017. At the time of the GPM overpass, the IVT magnitudes were once again increasing along the California coast to values $>1000 \mathrm{~kg} \mathrm{~m}^{-1} \mathrm{~s}^{-1}$ in association with a deepening surface low pressure system over the northeast Pacific and intensifying prefrontal LLJ. The opportune overpass of GPM across the middle of the AR and surface low pressure system (Fig. 1) enabled an evaluation of precipitation processes in the cross-frontal (along-GPM transect) direction. The GPM transect of maximum cross-track reflectivity illustrates stratiform brightband precipitation with embedded convective precipitation occurring both on the warm sector side of the maximum in IVT magnitude at $\sim 30^{\circ} \mathrm{N}$, $136.5^{\circ} \mathrm{W}$ and the cold sector side of the maximum in IVT magnitude at $\sim 33^{\circ} \mathrm{N}, 137.5^{\circ} \mathrm{W}$ (Fig. 5a). While the identified precipitation is fairly broad, there is a distinct maximum in the mean cross-track precipitation of $8.1 \mathrm{~mm} \mathrm{~h}^{-1}$ (the corresponding cross-track precipitation maximum is $52 \mathrm{~mm} \mathrm{~h}^{-1}$ ) located $\sim 250 \mathrm{~km}$ north of the IVT maximum, in the vicinity of the front (Fig. 5b). Additional smaller precipitation peaks are found further in the cold sector $\left(34^{\circ} \mathrm{N}, 138^{\circ} \mathrm{W}\right)$ and in the warm sector $\left(30^{\circ} \mathrm{N}, 136.5^{\circ} \mathrm{W}\right)$. For reference, the CFSR precipitation distribution along the transect has comparatively more precipitation falling in the warm sector and two distinct maxima that correspond roughly to GPM observations.

The CFSR profiles of wind, water vapor mixing ratio and $\theta_{e}$, indicating the position of the moist prefrontal LLJ, upper-level jet, and cold front (Fig. 5b), are used to evaluate the mechanisms by which the observed precipitation was generated. The transect of water vapor mixing ratio on 8 February 2017 contains two maxima at 
$850 \mathrm{hPa}$ across the AR, with one maximum of $8.4 \mathrm{~g} \mathrm{~kg}^{-1}$ along the cold front $(\sim 250 \mathrm{~km}$ poleward of the IVT maximum) as expected based on the results of Ralph et al. (2017b) and one maximum of $10.1 \mathrm{~g} \mathrm{~kg}^{-1}(\sim 50 \mathrm{~km}$ equatorward of the IVT maximum) corresponding to the pre-existing AR that the transect is centered upon (Fig. 5). The two individual water vapor maxima occur in proximity to precipitation maxima in both GPM and CFSR. Discerning the mechanisms that produced each precipitation maximum is aided by evaluating CAPE and frontogenesis along the transect (Fig. 5c) as shown by Cordeira et al. (2013; see their Figs. 4 and 7). The water vapor maximum ahead of the cold front contains CAPE values of $\sim 350 \mathrm{~J} \mathrm{~kg}^{-1}$ in the vicinity of strong vertical wind shear adjacent to the prefrontal LLJ maximum. While this CAPE value is not large (i.e., as compared to those values in overland severe convection), the moderately unstable, moist-neutral (i.e., near constant $\theta_{e}$ with height) environment combined with vertical wind shear across the AR likely generated and maintained convective precipitation. The water vapor maximum along the cold front is associated with both the production of stratiform precipitation over the cold front and convective precipitation in association with a shallow and narrow cold-frontal rainband (Jorgensen et al. 2003). The latter likely occurred in conjunction with forced ascent of the moist air ahead of the cold front, as determined by the collocation of a corridor of enhanced midtropospheric ascent with a region of lower-tropospheric frontogenesis (Fig. 5c) adjacent to the maximum in IVT magnitude (Oakley et al. 2018; Cannon et al. 2018). Here, frontogenesis is calculated at $850 \mathrm{hPa}$ using the Petterssen (1936) frontogenesis equation. The alongfront parallel structure of these two features and across-front displacement suggests a northwesterly tilt of the frontal circulation with height, which would suggest a shallow thermally direct ageostrophic circulation capable of providing enhanced low-level forcing for ascent of moist air in the region of the narrow cold-frontal rainband (Markowski and Richardson 2010). The low static stability aloft and weak surface instability associated with CAPE values of $\sim 200 \mathrm{~J} \mathrm{~kg}^{-1}$ supported the production of convective precipitation in this region of forced ascent. These results suggest that enhanced precipitation rates in ARs likely occur in association with multiple dynamical processes that may subsequently influence the water vapor budget in the AR (e.g., Cordeira et al. 2013).

The latent heat release associated with both convective and stratiform regions of precipitation is likely important to the evolution of the front, AR, and largerscale extratropical cyclone (Martin and Otkin 2004). For example, Lackmann (2002) determined that diabatic
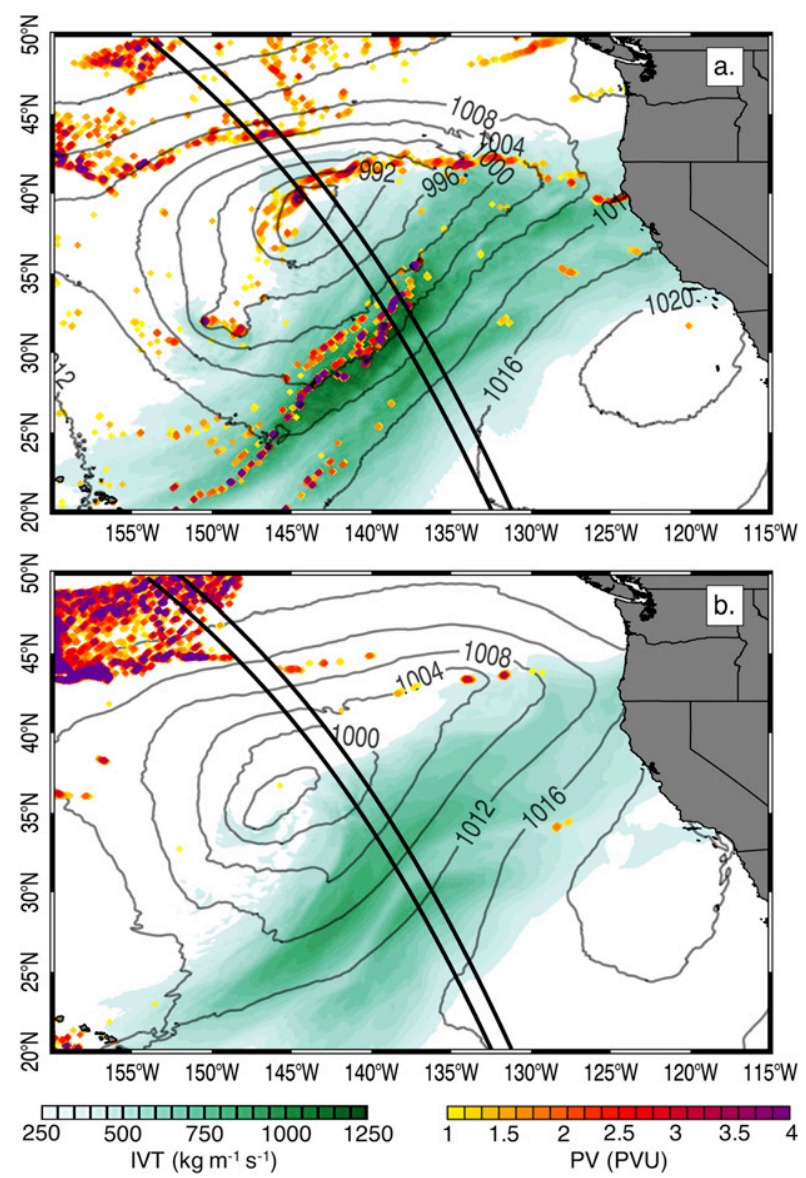

FIG. 7. WRF simulated sea level pressure (contours every $4 \mathrm{hPa}$ ), IVT magnitude ( $\mathrm{kg} \mathrm{m}^{-1} \mathrm{~s}^{-1}$; green colorfill), and 925-850-hPa PV (PVU; red colorfill) at 1200 UTC 8 Feb 2017 in the 9-km domain for the (a) control and (b) no latent heating experiments.

processes along a cold front in conjunction with the latent heat of condensation occurred in association with the production of lower-tropospheric PV that ultimately enhanced the magnitude of the prefrontal LLJ and concomitant lower-tropospheric moisture transport. Spectral latent heating estimates from GPM-DPR (Takayabu et al. 2017; Iguchi et al. 2018) correspond to the horizontal location of precipitation maxima (Fig. 6) with a crosstrack mean maximum of $>5.5 \mathrm{~K} \mathrm{~h}^{-1}$ located at an elevation of $\sim 3.5 \mathrm{~km}(\sim 800 \mathrm{hPa})$ and above the cold front $\sim 300 \mathrm{~km}$ north of the maximum in IVT magnitude. This maximum in latent heating is roughly collocated with the region of frontogenesis (Fig. 5c). In the next section we investigate how this region of latent heat release may subsequently influence the evolution of the front, AR, and larger-scale extratropical cyclone.

\section{b. Latent heat analysis using WRF}

The influence of latent heat release on the evolution of the front, AR, and larger-scale extratropical cyclone 


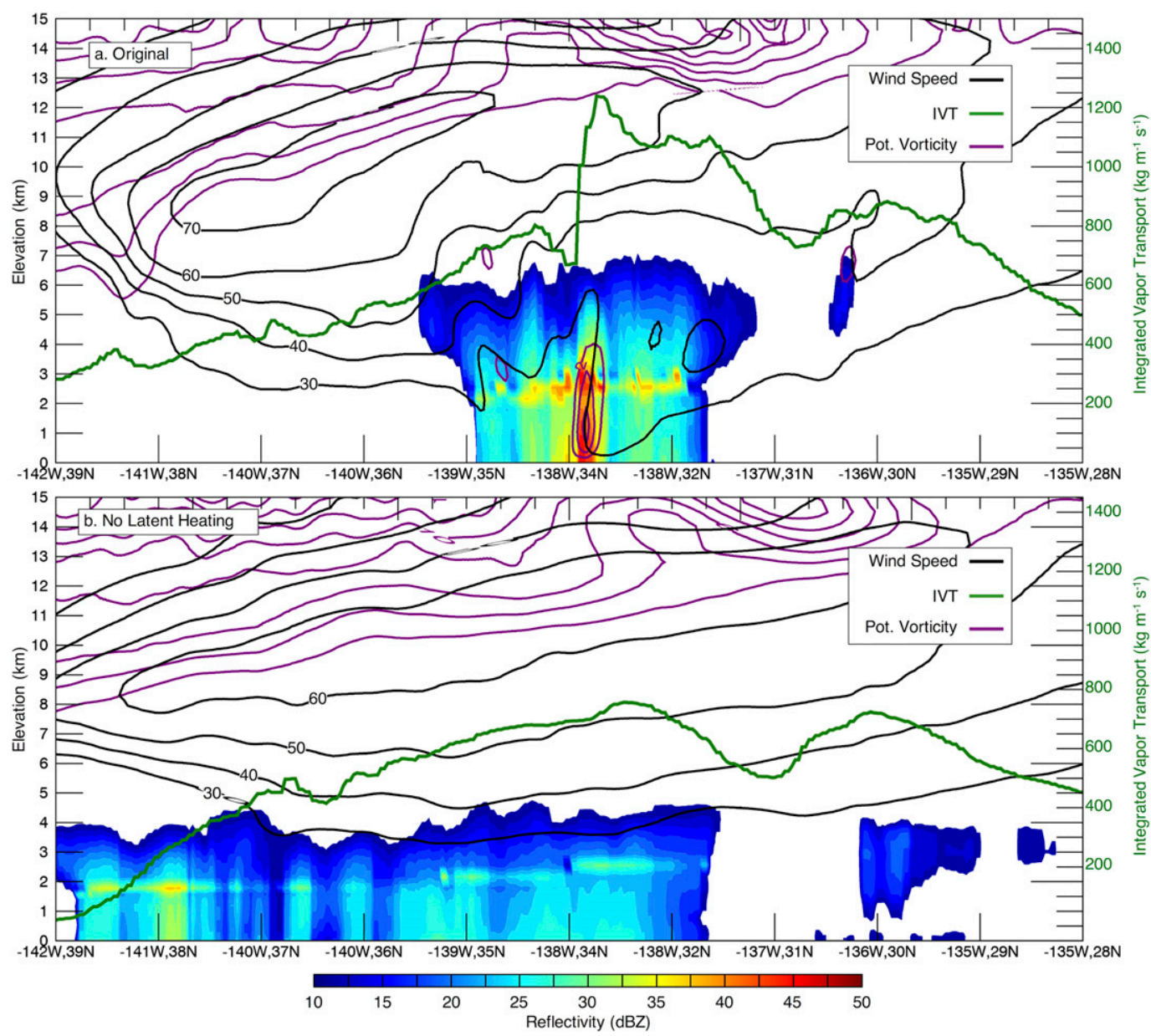

FIG. 8. WRF transect of simulated reflectivity (dBZ; colorfill), wind speed (black contours every $10 \mathrm{~m} \mathrm{~s}^{-1}$ ), PV (purple contours every 2 PVU starting at 2 PVU), and IVT $\left(\mathrm{kg} \mathrm{m}^{-1} \mathrm{~s}^{-1}\right.$; green line) along the center of the GPM overpass from the (a) control and (b) no-latent heating simulations at 1200 UTC 8 Feb 2017.

is investigated by comparing a control WRF simulation and a modified WRF simulation with no cumulus parameterization and no latent heating (see section 2). Note that Lackmann (2002) performed PV inversion to quantify the contribution of a given region of latent heat release to the strength of the prefrontal LLJ and water vapor transport. Here, we are able to infer feedbacks between these processes by turning off latent heat release from the microphysics and cumulus schemes across the entirety of the domain, but the modified simulation will inevitably be associated with additional changes in the evolution of the larger-scale extratropical cyclone that are not directly attributed to latent heat release along the AR cold front (e.g., due to PV perturbations near the warm conveyor belt or near the tropopause). Furthermore, the relative contribution of low-level diabatic PV to AR evolution will vary by case.

The analysis of 925-850-hPa PV and IVT in the 9-km WRF domain for both simulations illustrates a reduction of lower-tropospheric PV along the front and AR associated with no latent heating (Fig. 7). This reduction of low-tropospheric PV occurs in association with a large decrease in alongfront precipitation intensity and a complete lack of narrow cold-frontal rainband development (Fig. 8). The maximum value of IVT magnitude along the AR in the simulation without latent heating is reduced by $40 \%$ in the core of the AR $\left(892 \mathrm{~kg} \mathrm{~m}^{-1} \mathrm{~s}^{-1}\right.$ compared to $1479 \mathrm{~kg} \mathrm{~m}^{-1} \mathrm{~s}^{-1}$ in the control run), and the total IVT within the AR is reduced by $37 \%$, which largely agree with the results of Lackmann (2002). Note that locations near the extratropical cyclone and proximal to the inferred warm conveyor belt region [i.e., in the preferred regions of cyclogenesis (Davis 1992)] also featured a reduction in lower-tropospheric PV and changes in the intensity of the extratropical cyclone. The removal of latent heat release across the modified domain resulted in a drastic reduction of lower-tropospheric PV generation in these cyclogenesis-sensitive regions and 


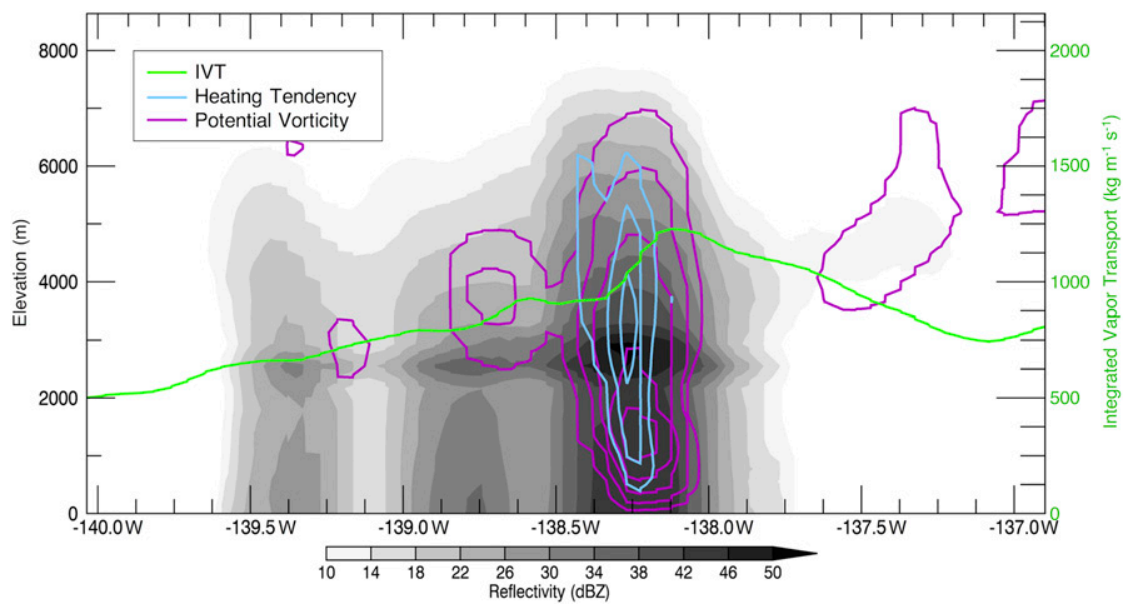

FIG. 9. WRF transect of the cross-track mean of simulated reflectivity (dBZ; grayshade), heating tendencies (cyan contours every $8 \mathrm{~K} \mathrm{~h}^{-1}$ starting at $8 \mathrm{~K} \mathrm{~h}^{-1}$ ), $\mathrm{PV}$ (purple contours every 2 PVU starting at 2 PVU), and IVT $\left(\mathrm{kg} \mathrm{m}^{-1} \mathrm{~s}^{-1}\right.$; green line) along the GPM overpass from the control simulation.

resulted in a weaker extratropical cyclone with a minimum sea level pressure $11 \mathrm{hPa}$ higher than in the control simulation ( $994 \mathrm{hPa}$ compared to $983 \mathrm{hPa}$ ). It is important to recognize that these changes to cyclone intensity and PV within the warm conveyor belt region are not likely (or at least not in large part or immediately) driven by changes in latent heat release along the AR (Fig. 7; Davis and Emanuel 1991; Martin and Otkin 2004). For example, a positive feedback likely exists among latent heat release, the intensification of water vapor transport along the AR, and resulting enhancement of precipitation, latent heat release, and lowertropospheric PV generation along the warm conveyor belt that cannot be evaluated using the current study (Davis et al. 1993).

To relate the generation of $\mathrm{PV}$ by precipitation in WRF, and its subsequent impact on AR evolution back to the GPM analyses performed in the previous section, we examine a transect of WRF variables from the control simulation in Fig. 7a corresponding to the location of the center of the GPM overpass (Fig. 8a). Here, because of uncertainty arising from initial condition error (assimilation and/or nudging were not used in these simulations), model physics, and unresolved scales (Warner 2011), the position of the AR is slightly different after a 24-h simulation than in the reanalysis or observations. The transect of simulated reflectivity and wind magnitude gives clear indication of a frontally forced precipitation maximum of similar magnitude to the GPM observations, though it does not indicate convective precipitation ahead of the IVT maximum, as was observed in CFSR and GPM. Presumably, the relatively stronger forced convection along the sustained cold front is more readily simulated than short-lived free convection in the warm sector (Warner 2011). The precipitation maximum along the reflectivity transect is collocated with a positive PV maximum of 8.3 PVU $\left(1 \mathrm{PVU}=10^{-6} \mathrm{~K} \mathrm{~kg}^{-1} \mathrm{~m}^{2} \mathrm{~s}^{-1}\right)$ at an elevation of $1 \mathrm{~km}$. The simulated case exhibits a sharp IVT discontinuity across the front, and the along AR winds at $1 \mathrm{~km}$ exhibited a difference of $33 \mathrm{~m} \mathrm{~s}^{-1}$ across the lower-tropospheric PV anomaly. The same wind magnitude response is not found in the no-latent heating simulation, which produced a weaker AR in the absence of diabatic heating tendencies and any circulation feedbacks from frontally forced precipitation (Fig. 8b).

Combined WRF heating tendencies from the cumulus and microphysics schemes plotted over the frontal rainband and PV maximum in Fig. 9 demonstrate the important role of latent heating in generating the PV anomaly and thus modifying AR evolution. Furthermore, a comparison between Figs. 9 and 6 confirm that the model's representation of the precipitation and circulation feedbacks described here are consistent with GPM-DPR SLH observations and theory. In fact, the observed and modeled latent heating maxima are both found between 3 and $4 \mathrm{~km}$ and are a remarkably good match in terms of their vertical and horizontal extents, though modeled heating was stronger.

\section{Results: Composite analyses}

The importance of frontal forcing as a primary precipitation mechanism that was detailed in the 8 February 2017 case study is also apparent in an evaluation of 192 GPM-DPR transects across ARs during October-April 

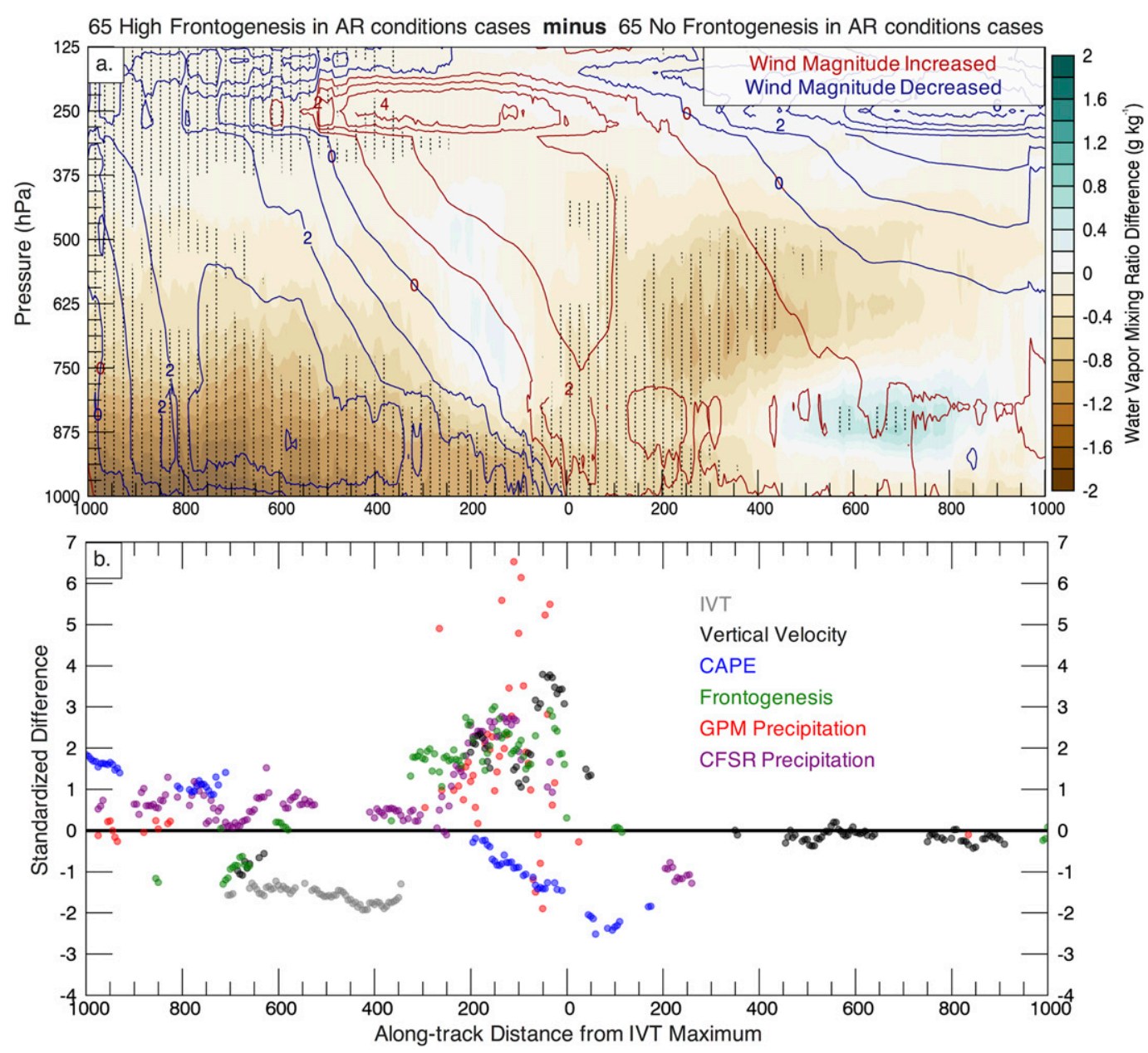

FIG. 10. (a) Differences in the composite mean water vapor mixing ratio (grayshade), and wind magnitude (contours) between the $65 \mathrm{AR}$ transects with the highest frontogenesis values minus the $65 \mathrm{AR}$ transects with the lowest frontogenesis values. The red (blue) contours indicate where wind magnitude is larger in high frontogenetic (low frontogenetic) cases. The stippling indicates significance in water vapor mixing ratio differences $(p<0.05$; calculated by bootstrapping for grid points that exhibited significantly different distributions as determined by a nonparametric Mann-Whitney $U$ test). (b) The standardized differences for 1D diagnostic variables across the transect are shown. Only values where the distributions of each variable in the high frontogenetic and low frontogenetic cases were significantly different are shown.

2014-18. The 192 transects are partitioned into the 65 (one-third of the total) that contained the largest frontogenesis values in the AR transect and compared to the 65 with the weakest frontogenesis values (negative values indicate frontolysis). Note that the centroids of the individual AR transects in the high- and lowfrontogenesis populations are scattered spatially so that the results presented here are not strongly biased by systemic latitudinal or longitudinal differences between events in each of the composite categories (e.g., subtropical versus midlatitude transects).

The composite differences in wind magnitude between these two populations of transects indicate that increased frontogenesis generally produces a stronger front, a narrower corridor of enhanced IVT magnitudes along the AR, and a stronger $\left(\sim 2-4 \mathrm{~m} \mathrm{~s}^{-1}\right)$ prefrontal LLJ (Fig. 10a). The 1000-850-hPa along-AR component of the wind in strong frontogenesis cases is enhanced (reduced) on the warm (cold)-sector side of the front (Fig. 10a), and a stronger dipole of cross-AR wind straddles the IVT maximum, indicating enhanced convergence that maximizes along the front $\sim 50 \mathrm{~km}$ toward the cold-sector side of the IVT maximum (Fig. 11). The difference plot also illustrates that the strong frontogenetic case composite contained significantly $\left(\sim 1 \mathrm{~g} \mathrm{~kg}^{-1}\right)$ lower water vapor mixing ratio values near the surface within the AR and north of the cold front and nonsignificant differences in mixing ratio values along the 

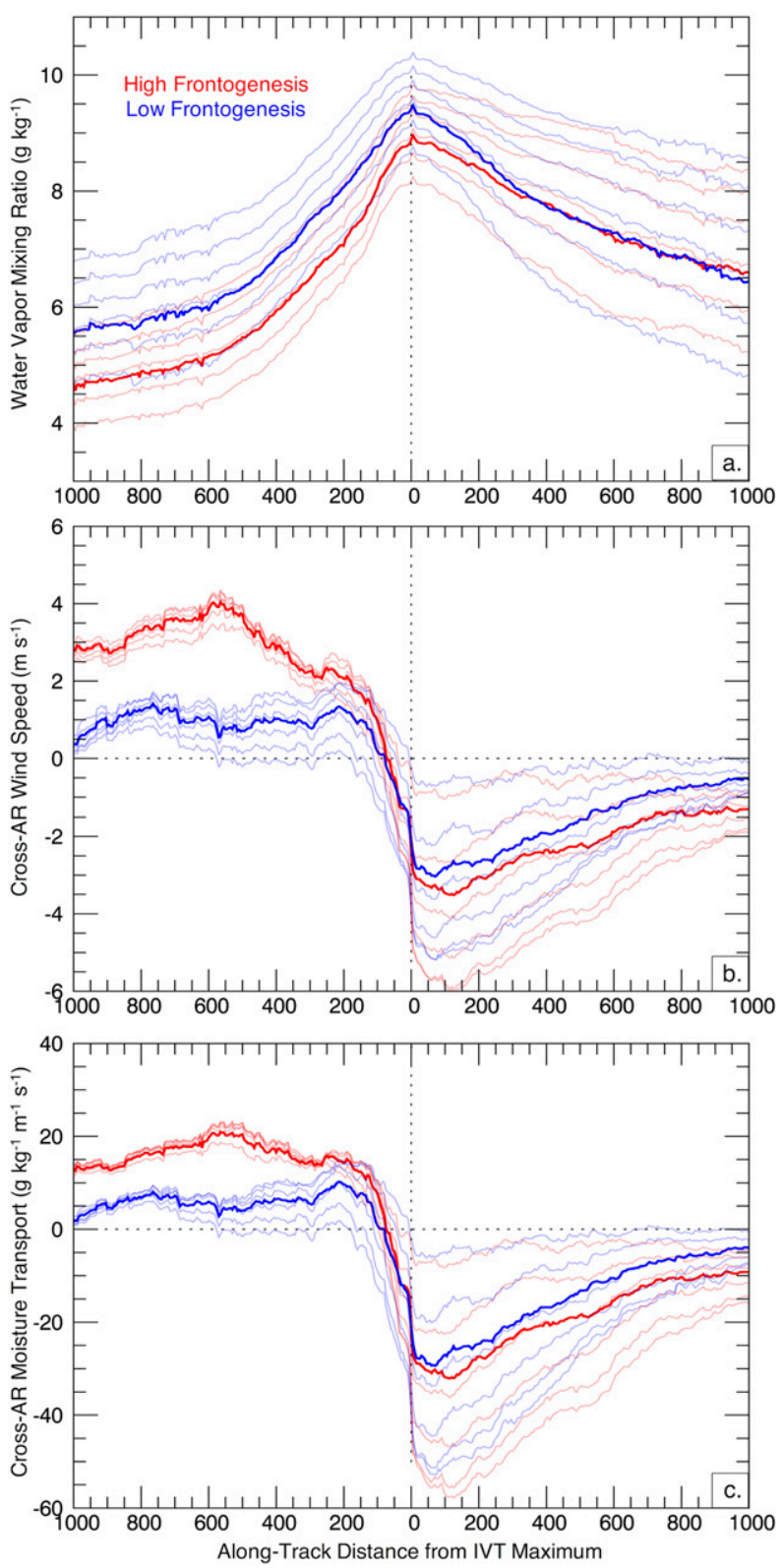

FIG. 11. Thick lines identify 1000-850-hPa layer-averaged (a) water vapor mixing ratio, (b) cross-AR wind speed, and (c) cross-AR moisture transport for the high frontogenesis case composite (red) and the low frontogenesis case composite (blue). Values from each of the six model levels used in the 1000-850-hPa layer average are shown in thin colored lines for their respective categories.

sloped region over the cold front (between 850 and $625 \mathrm{hPa}$ on the cold-sector side of the IVT maximum; Fig. 10a).

While it was noted that the results are not strongly biased by systemic differences in the position of the transects between categories, the strong frontogenesis cases do have a mean latitude of $39.5^{\circ} \mathrm{N}$ that is $\sim 2.5^{\circ}$ north of the mean latitude of weak frontogenesis cases. This disparity is consistent with the fact that frontogenesis is generally favored in the midlatitudes (Thomas and Schultz 2019). Additional testing to control for the $\sim 2.5^{\circ}$ mean latitudinal difference between the frontogenesis categories by limiting analyses to $\left(35^{\circ}-45^{\circ} \mathrm{N}\right.$, $\left.155^{\circ}-125^{\circ} \mathrm{W}\right)$ - a region that has 34 AR centroids in both the strong and weak frontogenesis categories and whose latitude distributions have means of $40.3^{\circ}$ and $40.5^{\circ} \mathrm{N}$, respectively-demonstrated a strengthening of the along-AR wind signal discussed here. Furthermore, the moisture differences in the cold-sector were further exacerbated while those in the AR core were diminished (not shown). Overall, controlling for latitude produced a cleaner signal, though further analyses utilized all AR transects over the full study domain both to bolster the sample size and to avoid spatially limited conclusions about AR processes.

The transects associated with the set of 65 strong frontogenesis cases also contain large differences in several $1 \mathrm{D}$ variables along the transect in the region within $250 \mathrm{~km}$ on the cold side of the maximum IVT magnitude, which illustrate the importance of frontogenesis to the generation of precipitation (Fig. 10b). The strong frontogenesis composite is associated with a $33 \%$ reduction in maximum CAPE values due to the increase in water vapor mixing ratio aloft and decrease near the surface (Fig. 10a); the resulting increased $\theta_{e}$ gradient increases static stability. Despite the comparative increase in static stability, stronger vertical motion is observed in the vicinity of the front likely associated with forced ascent. The stronger frontogenesis and stronger vertical motion is illustrative of a thermally direct ageostrophic circulation in the plane of the lowertropospheric front that enhances moisture convergence (Fig. 11c) and is conducive to the development of banded precipitation structures in conjunction with the release of potential or symmetric instability, particularly in deepening baroclinic systems (e.g., Markowski and Richardson 2010; Funk 2011). Based on the results of Lackmann (2002) and the previously shown case study, these highly frontogenetic cases are likely also associated with the development of precipitation over the front that produces a local maximum in lower-tropospheric PV that may intensify the prefrontal LLJ and enhance water vapor transport and IVT within the AR.

Figure 10b demonstrates that both CFSR and GPMDPR generate significantly more precipitation on the cold-sector side of the IVT maximum in the region of enhanced vertical ascent in strong frontogenesis cases. Comparisons of GPM-derived latent heating between the two frontogenesis populations also show an $\sim 5-10 \mathrm{~K} \mathrm{~h}^{-1}$ increase in latent heating for highly frontogenetic cases 

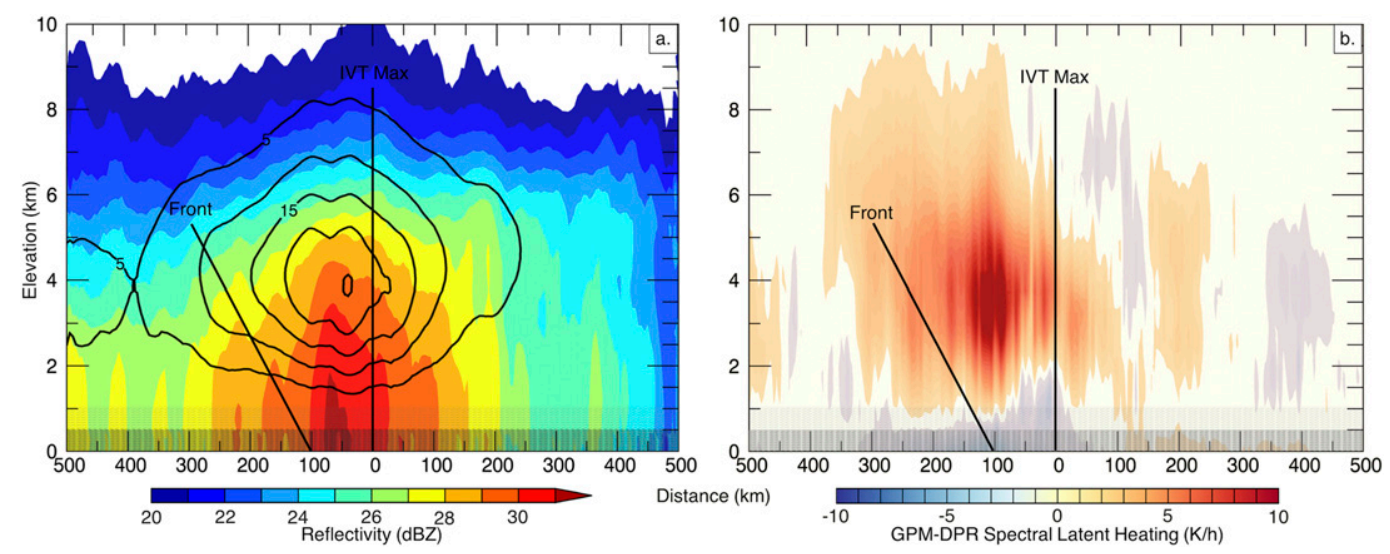

FIG. 12. (a) Composite of reflectivity (colorfill) and latent heating (contour) from 192 transects. (b) Differences in the composite mean GPM-DPR latent heating estimate (colorfill) between the $65 \mathrm{AR}$ transects with the highest frontogenesis values and the $65 \mathrm{AR}$ transects with the lowest frontogenesis. The average front location is indicated in schematic form by the diagonal black line. The vertical green line indicates the IVT maximum. The gray stippling below 0.5 and $1 \mathrm{~km}$ elevation indicates the region where surface clutter affects the nadir and edge bins of the GPM swath, respectively.

that is centered between 3 and $4 \mathrm{~km}$ altitude $\sim 100 \mathrm{~km}$ on the cold-sector side of maximum IVT magnitude (Fig. 12b) that corresponds well to the composite latent heating maximum from all cases (Fig. 12a) and transect maxima in vertical motion and precipitation (Fig. 10b). The magnitude of the difference in latent heating between strong frontogenesis and weak frontogenesis composites relative to the composite of all transects instills confidence in the robustness of the influence of frontogenesis on precipitation and atmospheric heating despite uncertainties in the retrieval of latent heating (Tao et al. 2019). The positive vertical gradient in latent heating is associated with a hypothesized increase in lower-tropospheric PV at $\sim 1 \mathrm{~km}$ (Lackmann 2002) that is surmised to contribute to the intensification of the prefrontal LLJ as see in Fig. 10a and observed in the 8 February 2017 case study (Fig. 7), though this could only be confirmed by a large number of additional numerical experiments.

\section{Conclusions}

Atmospheric rivers (AR) are the dominant source of extreme precipitation events on the U.S. West Coast. While precipitation processes associated with these events are typically studied at landfall, here the production of precipitation and its effect on AR evolution are investigated over the northeast Pacific Ocean using satellite Global Precipitation Measurement DualFrequency Precipitation Radar (GPM-DPR), reanalyses, and modeling experiments. Analysis of both a single impactful case study and a large sample of GPM overpasses of ARs yield insight into the prevalence of mesoscale precipitation mechanisms.
The impactful 8 February 2017 California precipitation event revealed that cyclogenesis and frontogenesis along a preexisting AR led to intense observed precipitation over a strengthening cold front, just north of the IVT maximum, which generated a latent heating anomaly centered between 3 and $4 \mathrm{~km}$ elevation (Figs. 5 and 6). A WRF simulation of this event further demonstrated that a potential vorticity maximum developed below the observed latent heating anomaly, and a second experiment to define the effect of latent heating on event evolution clarified that frontogenetically forced precipitation, latent heating, and subsequent potential vorticity generation strengthened water vapor transport in the AR and accelerated its propagation toward landfall (Fig. 8). The mechanisms that generated precipitation along the AR in the 8 February 2017 case study were further investigated across 192 AR transects over the northeast Pacific Ocean between 2014 and 2018. Composite analyses of GPM-DPR and CFSR conditioned on the strength of frontogenesis over the AR indicated that the development of ageostrophic vertical motions and subsequent precipitation and latent heating occurred often and preferentially in highly frontogenetic events (Figs. 10 and 12).

The motivation for evaluating observed precipitation and its underlying mechanisms relative to AR evolution arises from known feedbacks between them (e.g., Lackmann 2002) and the potential for error in representing these processes to have a large detrimental impact on model skill (Schäfler et al. 2018). For example, Reynolds et al. (2019) used a moist adjoint model (Amerault et al. 2008) to conclude that, during the 201617 winter season, 1-day precipitation forecasts over California ahead of AR landfall were most sensitive to 
moisture and wind perturbations on the subsaturated edges of ARs and in the warm conveyor belt region, where forced ascent and the production of latent heating are prevalent. Although the precipitation mechanisms investigated here are not absent from global-scale models, their difficulty in accurately representing resultant precipitation likely translates to uncertainty in forecasting heating tendencies, their feedbacks with AR evolution, and ultimately AR impacts upon landfall in the western United States. These findings motivate additional research to quantify the influence of precipitation within ARs on their water vapor budget and evolution, and highlight that future efforts to improve AR forecast skill may benefit from increased attention to model representation of observed precipitation processes ahead of landfall.

Acknowledgments. This research was supported by the California Department of Water Resources and the U.S. Army Corps of Engineers (USACE) as part of Forecast Informed Reservoir Operations (FIRO). Funding was also provided by the Orange County Water District. The NCEP-CFSR data used in this research were developed by the NOAA. Observational GPM datasets are made available through a joint collaboration between JAXA and NASA, with data access also made available by GES DISC. WRF simulations were performed on the San Diego Supercomputing Center's COMET resource through NSF XSEDE.

\section{REFERENCES}

Amerault, C., X. Zou, and J. Doyle, 2008: Tests of an adjoint mesoscale model with explicit moist physics on the cloud scale. Mon. Wea. Rev., 136, 2120-2132, https://doi.org/10.1175/ 2007MWR2259.1.

Awaka, J., M. Le, V. Chandrasekar, N. Yoshida, T. Higashiuwatoko, T. Kubota, and T. Iguchi, 2016: Rain type classification algorithm module for GPM dual-frequency precipitation radar. J. Atmos. Oceanic Technol., 33, 1887-1898, https://doi.org/ 10.1175/JTECH-D-16-0016.1.

Baldwin, D., E. Hsie, and R. A. Anthes, 1984: Diagnostic studies of a two-dimensional simulation of frontogenesis in a moist atmosphere. J. Atmos. Sci., 41, 2686-2700, https:// doi.org/10.1175/1520-0469(1984)041<2686:DSOATD > 2.0.CO;2.

Booth, J. F., C. M. Naud, and J. Jeyaratnam, 2018: Extratropical cyclone precipitation life cycles: A satellite-based analysis. Geophys. Res. Lett., 45, 8647-8654, https://doi.org/10.1029/ 2018 GL078977.

Cannon, F., F. M. Ralph, A. M. Wilson, and D. P. Lettenmaier, 2017: GPM satellite radar measurements of precipitation and freezing level in atmospheric rivers: Comparison with groundbased radars and reanalyses. J. Geophys. Res. Atmos., 122, 12 747-12 764, https://doi.org/10.1002/2017JD027355.

, C. Hecht, J. Cordeira, and F. M. Ralph, 2018: Synoptic and mesoscale forcing of Southern California extreme precipitation. J. Geophys. Res. Atmos., 123, 13714-13730, https:// doi.org/10.1029/2018JD029045.
Chan, D., and H. R. Cho, 1991: The dynamics of moist frontogenesis in a semi-geostrophic model. Atmos. Ocean, 29 (1), 85-101.

Cordeira, J. M., F. M. Ralph, and B. J. Moore, 2013: The development and evolution of two atmospheric rivers in proximity to western North Pacific tropical cyclones in October 2010. Mon. Wea. Rev., 141, 4234-4255, https://doi.org/10.1175/ MWR-D-13-00019.1.

Davis, C. A., 1992: A potential-vorticity diagnosis of the importance of initial structure and condensational heating in observed extratropical cyclogenesis. Mon. Wea. Rev., 120, 2409-2428, https://doi.org/10.1175/1520-0493(1992)120<2409: APVDOT $>2.0 . \mathrm{CO} ; 2$.

, and K. A. Emanuel, 1991: Potential vorticity diagnostics of cyclogenesis. Mon. Wea. Rev., 119, 1929-1953, https://doi.org/ 10.1175/1520-0493(1991)119<1929:PVDOC >2.0.CO;2.

- M. T. Stoelinga, and Y. Kuo, 1993: The integrated effect of condensation in numerical simulations of extratropical cyclogenesis. Mon. Wea. Rev., 121, 2309-2330, https://doi.org/ 10.1175/1520-0493(1993)121<2309:TIEOCI>2.0.CO;2.

Dettinger, M., 2013: Atmospheric rivers as drought busters on the U.S. West Coast. J. Hydrometeor., 14, 1721-1732, https:// doi.org/10.1175/JHM-D-13-02.1.

Doyle, J. D., C. Amerault, C. A. Reynolds, and P. A. Reinecke, 2014: Initial condition sensitivity and predictability of a severe extratropical cyclone using a moist adjoint. Mon. Wea. Rev., 142, 320-342, https://doi.org/10.1175/MWR-D-13-00201.1.

Funk, T., 2011: A practical, basic guide to quasi-geostrophic theory, response to geostrophic deformation, ageostrophic motion and jet streaks. National Weather Service, Louisville, KY, 26 pp., https:/www.weather.gov/media/lmk/soo/QG_Theory_Review.pdf.

Grell, G. A., and D. Devenyi, 2002: A generalized approach to parameterizing convection combining ensemble and data assimilation techniques. Geophys. Res. Lett., 29, 1693, https:// doi.org/10.1029/2002GL015311.

Hong, S. Y., Y. Noh, and J. Dudhia, 2006: A new vertical diffusion package with an explicit treatment of entrainment processes. Mon. Wea. Rev., 134, 2318-2341, https://doi.org/10.1175/ MWR3199.1.

Hou, A. Y., and Coauthors, 2014: The Global Precipitation Measurement Mission. Bull. Amer. Meteor. Soc., 95, 701-722, https://doi.org/10.1175/BAMS-D-13-00164.1.

Hsie, E., R. A. Anthes, and D. Keyser, 1984: Numerical simulation of frontogenesis in a moist atmosphere. J. Atmos. Sci., 41, 2581-2594, https://doi.org/10.1175/1520-0469(1984)041<2581: NSOFIA $>2.0 . \mathrm{CO} ; 2$.

Iguchi, T., S. Shinta, R. Menghini, N. Yoshida, J. Awaka, M. Le, V. Chandrasekar, and T. Kubota, 2010: GPM/DPR Level-2. Algorithm Theoretical Basis Doc., 68 pp., https://pps.gsfc.nasa.gov/ atbd.html.

_, and Coauthors, 2018: GPM/DPR Level-2 Algorithm Theoretical Basis Document. Japan Aerospace Exploration Agency, 127 pp., https://www.eorc.jaxa.jp/GPM/doc/algorithm/ ATBD_DPR_201811_with_Appendix3b.pdf.

Jiménez, P. A., J. Dudhia, J. F. González-Rouco, J. Navarro, J. P. Montávez, and E. García-Bustamante, 2012: A revised scheme for the WRF surface layer formulation. Mon. Wea. Rev., 140, 898-918, https://doi.org/10.1175/MWR-D-11-00056.1.

Jorgensen, D. P., Z. Pu, P.O. Persson, and W. Tao, 2003: Variations associated with cores and gaps of a Pacific narrow cold frontal rainband. Mon. Wea. Rev., 131, 2705-2729, https://doi.org/ 10.1175/1520-0493(2003)131<2705:VAWCAG > 2.0.CO;2.

Kuo, Y., M. A. Shapiro, and E. G. Donall, 1991: The interaction between baroclinic and diabatic processes in a numerical simulation 
of a rapidly intensifying extratropical marine cyclone. Mon. Wea. Rev., 119, 368-384, https://doi.org/10.1175/1520-0493(1991) $119<0368$ :TIBBAD $>2.0$. CO 2 .

Lackmann, G. M., 2002: Cold-frontal potential vorticity maxima, the low-level jet, and moisture transport in extratropical cyclones. Mon. Wea. Rev., 130, 59-74, https://doi.org/10.1175/ 1520-0493(2002)130<0059:CFPVMT >2.0.CO;2.

, and J. R. Gyakum, 1999: Heavy cold-season precipitation in the northwestern United States: Synoptic climatology and an analysis of the flood of 17-18 January 1986. Wea. Forecasting, 14, 687-700, https://doi.org/10.1175/1520-0434(1999)014<0687: HCSPIT $>2.0 . C O ; 2$.

Lavers, D. A., D. E. Waliser, F. M. Ralph, and M. D. Dettinger, 2016: Predictability of horizontal water vapor transport relative to precipitation: Enhancing situational awareness for forecasting western U.S. extreme precipitation and flooding. Geophys. Res. Lett., 43, 2275-2282, https://doi.org/10.1002/2016GL067765.

— M. J. Rodwell, D. S. Richardson, F. M. Ralph, J. D. Doyle, C. A. Reynolds, V. Tallapragada, and F. Pappenberger, 2018: The gauging and modeling of rivers in the sky. Geophys. Res. Lett., 45, 7828-7834, https://doi.org/10.1029/2018GL079019.

Markowski, P., and Y. Richardson, 2010: Mesoscale Meteorology in Midlatitudes. Wiley-Blackwell, $430 \mathrm{pp}$.

Martin, A., F. M. Ralph, R. Demirdjian, L. DeHaan, R. Weihs, J. Helly, D. Reynolds, and S. Iacobellis, 2018: Evaluation of atmospheric river predictions by the WRF Model using aircraft and regional mesonet observations of orographic precipitation and its forcing. J. Hydrometeor., 19, 1097-1113, https://doi.org/10.1175/JHM-D-17-0098.1.

Martin, J. E., and J. A. Otkin, 2004: The rapid growth and decay of an extratropical cyclone over the central Pacific Ocean. Wea. Forecasting, 19, 358-376, https://doi.org/10.1175/15200434(2004)019<0358:TRGADO > 2.0.CO;2.

Mlawer, E. J., S. J. Taubman, P. D. Brown, M. J. Iacono, and S. A. Clough, 1997: Radiative transfer for inhomogeneous atmospheres: RRTM, a validated correlated-k model for the longwave. J. Geophys. Res., 102, 16 663-16 682, https://doi.org/ 10.1029/97JD00237.

Montgomery, M.T., and B. F. Farrell, 1991: Moist surface frontogenesis associated with interior potential vorticity anomalies in a semigeostrophic model. J. Atmos. Sci., 48, 343-368, https://doi.org/10.1175/1520-0469(1991)048<0343:MSFAWI> 2.0.CO;2.

Neiman, P. J., B. J. Moore, A. B. White, G. A. Wick, J. Aikins, D. L. Jackson, J. R. Spackman, and F. M. Ralph, 2016: An airborne and ground-based study of a long-lived and intense atmospheric river with mesoscale frontal waves impacting California during CalWater-2014. Mon. Wea. Rev., 144, 1115-1144, https://doi.org/ 10.1175/MWR-D-15-0319.1.

Oakley, N. S., F. Cannon, R. Munroe, J. T. Lancaster, D. Gomberg, and F. M. Ralph, 2018: Brief communication: Meteorological and climatological conditions associated with the 9 January 2018 post-fire debris flows in Montecito and Carpinteria California, USA. Nat. Hazards Earth Syst. Sci., 18, 3037-3043, https://doi.org/10.5194/nhess-18-3037-2018.

Petterssen, S., 1936: Contribution to the theory of frontogenesis. Geofys. Publ., 11 (6), 1-27.

Posselt, D. J., and J. E. Martin, 2004: The effect of latent heat release on the evolution of a warm occluded thermal structure. Mon. Wea. Rev., 132, 578-599, https://doi.org/10.1175/15200493(2004)132<0578:TEOLHR >2.0.CO;2.

Ralph, F. M., P. J. Neiman, and G. A. Wick, 2004: Satellite and CALJET aircraft observations of atmospheric rivers over the eastern North Pacific Ocean during the winter of 1997/98. Mon. Wea. Rev., 132, 1721-1745, https://doi.org/10.1175/15200493(2004)132<1721:SACAOO > 2.0.CO;2.

—, E. Sukovich, D. Reynolds, M. Dettinger, S. Weagle, W. Clark, and P. J. Neiman, 2010: Assessment of extreme quantitative precipitation forecasts and development of regional extreme event thresholds using data from HMT-2006 and COOP observers. J. Hydrometeor., 11, 1286-1304, https://doi.org/10.1175/ 2010JHM1232.1.

— quantify the roles of atmospheric rivers and aerosols in modulating U.S. West Coast precipitation in a changing climate. Bull. Amer. Meteor. Soc., 97, 1209-1228, https://doi.org/ 10.1175/BAMS-D-14-00043.1.

— , and Coauthors, 2017a: Atmospheric rivers emerge as a global science and applications focus. Bull. Amer. Meteor. Soc., 98, 1969-1973, https://doi.org/10.1175/BAMS-D-16-0262.1.

_ - and Coauthors, 2017b: Dropsonde observations of total integrated water vapor transport within North Pacific atmospheric rivers. J. Hydrometeor., 18, 2577-2596, https://doi.org/ 10.1175/JHM-D-17-0036.1.

Reeves, H. D., and G. M. Lackmann, 2004: An investigation of the influence of latent heat release on cold-frontal motion. Mon. Wea. Rev., 132, 2864-2881, https://doi.org/10.1175/MWR2827.1.

Reynolds, C. A., J. D. Doyle, F. M. Ralph, and R. Demirdjian, 2019: Adjoint sensitivity of North Pacific atmospheric river forecasts. Mon. Wea. Rev., 147, 1871-1897, https://doi.org/ 10.1175/MWR-D-18-0347.1.

Rutz, J. J., W. J. Steenburgh, and F. M. Ralph, 2014: Climatological characteristics of atmospheric rivers and their inland penetration over the western United States. Mon. Wea. Rev., 142 , 905-921, https://doi.org/10.1175/MWR-D-13-00168.1.

Saha, S., and Coauthors, 2010: The NCEP Climate Forecast System Reanalysis. Bull. Amer. Meteor. Soc., 91, 1015-1058, https:// doi.org/10.1175/2010BAMS3001.1.

_ , and Coauthors, 2014: The NCEP Climate Forecast System version 2. J. Climate, 27, 2185-2208, https://doi.org/10.1175/ JCLI-D-12-00823.1.

Schäfler, A., and Coauthors, 2018: The North Atlantic waveguide and downstream impact experiment. Bull. Amer. Meteor. Soc., 99, 1607-1637, https://doi.org/10.1175/BAMS-D-17-0003.1.

Skamarock, W. C., and Coauthors, 2008: A description of the Advanced Research WRF version 3. NCAR Tech. Note NCAR/ TN-475+STR, 113 pp., https://doi.org/10.5065/D68S4MVH.

Skofronick-Jackson, G., and Coauthors, 2017: The Global Precipitation Measurement (GPM) mission for science and society. Bull. Amer. Meteor. Soc., 98, 1679-1695, https:// doi.org/10.1175/BAMS-D-15-00306.1.

—, D. Kirschbaum, W. Petersen, G. Huffman, C. Kidd, E. Stocker, and R. Kakar, 2018: The Global Precipitation Measurement (GPM) mission's scientific achievements and societal contributions: Reviewing four years of advanced rain and snow observations. Quart. J. Roy. Meteor. Soc., 144, 27-48, https:// doi.org/10.1002/qj.3313.

Takayabu, Y. N., A. Hamada, C. Yokoyama, Y. Ikuta, S. Shige, M. Yamaji, and T. Kubota, 2017: GPM SLH: Convective latent heating estimated with GPM dual-frequency precipitation radar data. 2017 Fall Meeting, New Orleans, LA, Amer. Geophys. Union, Abstract H33J-05.

Tao, W., T. Iguchi, and S. Lang, 2019: Expanding the Goddard CSH algorithm for GPM: New extratropical retrievals. J. Appl. Meteor. Climatol., 58, 921-946, https://doi.org/10.1175/JAMCD-18-0215.1. 
Thomas, C. M., and D. M. Schultz, 2019: Global climatologies of fronts, airmass boundaries, and airstream boundaries: Why the definition of "front" matters. Mon. Wea. Rev., 147, 691717, https://doi.org/10.1175/MWR-D-18-0289.1.

Thompson, G., P. R. Field, R. M. Rasmussen, and W. D. Hall, 2008 Explicit forecasts of winter precipitation using an improved bulk microphysics scheme. Part II: Implementation of a new snow parameterization. Mon. Wea. Rev., 136, 5095-5115, https://doi.org/10.1175/2008MWR2387.1.

Thorpe, A. J., and K. A. Emanuel, 1985: Frontogenesis in the presence of small stability to slantwise convection. J. Atmos. Sci., 42, 1809-1824, https://doi.org/10.1175/1520-0469(1985) 042<1809:FITPOS > 2.0.CO;2.

Vano, J. A., M. D. Dettinger, R. Cifelli, D. Curtis, A. Dufour, K. Miller, J. R. Olsen, and A. M. Wilson, 2019: Hydroclimatic extremes as challenges for the water management community: Lessons from Oroville Dam and Hurricane Harvey [in "Explaining extremes of 2017 from a climate perspective"].
Bull. Amer. Meteor. Soc., 100, S9-S14, https://doi.org/10.1175/ BAMS-D-18-0219.1.

Warner, T. T., 2011: Numerical Weather and Climate Prediction. Cambridge University Press, $526 \mathrm{pp}$.

White, A. B., B. J. Moore, D. J. Gottas, and P. J. Neiman, 2019: Winter storm conditions leading to excessive runoff above California's Oroville Dam during January and February 2017. Bull. Amer. Meteor. Soc., 100, 55-70, https://doi.org/10.1175/ BAMS-D-18-0091.1.

Wick, G. A., P. J. Neiman, F. M. Ralph, and T. M. Hamill, 2013: Evaluation of forecasts of the water vapor signature of atmospheric rivers in operational numerical weather prediction models. Wea. Forecasting, 28, 1337-1352, https://doi.org/ 10.1175/WAF-D-13-00025.1.

Zhu, Y., and R. E. Newell, 1998: A proposed algorithm for moisture fluxes from atmospheric rivers. Mon. Wea. Rev., 126, 725-735, https://doi.org/10.1175/1520-0493(1998)126<0725:APAFMF> 2.0.CO;2. 